\title{
Comparison of Use of Misoprostol versus Manual Vacuum Aspiration in the Treatment of Incomplete Abortion
}

\author{
Bishal Khaniyal, Rashmi Yadav ${ }^{2}$ \\ ${ }^{1}$ Department of Obstetrics and Gynaecology, Institute of Medicine, Teaching Hospital, Kathmandu, Nepal \\ ${ }^{2}$ Department of Obstetrics and Gynaecology, National Academy of Medical Sciences, Bir Hospital, Kathmandu, Nepal
}

\begin{abstract}
Introduction: Early pregnancy failure is a major health problem throughout the world. Expulsion of some but not all products of conception before 20 weeks of pregnancy abortion is an incomplete abortion. This study was to find about the safety, efficacy, and acceptability of misoprostol in comparison to manual vacuum aspiration for the treatment of incomplete abortion so the safe and convenient method can be used in diverse settings in different parts of our country.
\end{abstract}

Materials and Methods: A prospective comparative interventional study carried out between October 2011 to March 2012 AD (Kartik 2068 to Chaitra 2068 BS) in Paropakar Maternity and Women's Hospital, Thapathali. All eligible women with a diagnosis of incomplete abortion of $<13$ weeks of gestation either from LMP or Ultrasound were divided into two groups. Group 1 includes all odd numbers of cases under study group to whom $600 \mathrm{mcg}$ Misoprostol was given orally. Group 2 includes all even the number of cases under study group to whom manual vacuum aspiration was done.

Results: Out of 60 women enrolled in the study, 30 were enrolled in Group 1(Misoprostol P.O.) and 30 in Group 2 (manual vacuum aspiration). The study showed no significant difference in the efficacy of the Misoprostol as compared to manual vacuum aspiration ( $93.33 \%$ vs. $100 \%$ ).
Correspondence:

Dr. Khaniya Bisha

Teaching Assistants, 'Department of Obstetrics and Gynaecology

Institute of Medicine, Teaching Hospital,

Kathmandu, Nepal

ORCID ID: 0000-0002-7191-0955

Email: bishalkhaniya92@gmail.com

Submitted $: 30^{\text {th }}$ November 2019

Accepted : $23^{\text {rd }}$ December 2019

Source of Support: None

Conflict of Interest: No

Citation: Khaniya B, Yadav R. Comparison of use of misoprostol versus manual vacuum aspiration in the treatment of incomplete abortion. NMJ 2019;2 (2): 239-42. DOI 10.3126/nmj.v2i2.25855

Conclusions: The efficacy of oral Misoprostol is as effective as manual vacuum aspiration in the treatment of first trimester incomplete abortion with comparable success rate.

Keywords: Abortion; Incomplete; Vacuum aspiration; Misoprostol, MVA

\section{INTRODUCTION}

Early pregnancy failure is a major health problem throughout the world. According to an estimate, approximately $15 \%$ of all pregnancy ends to a spontaneous miscarriage, which means approximately 46 millions occur annually. ${ }^{1}$ Many of these are performed illegally in unsafe situations resulting in approximately 47000 deaths worldwide in 2008. Complications from unsafe abortion accounted for an estimated $13 \%$ of all maternal death worldwide. $^{1}$
Expulsion of some but not all products of conception before 20 weeks of pregnancy abortion is incomplete abortion. ${ }^{2}$ Evacuation of the uterus in incomplete abortion in which uterine size is $<12$ weeks is usually performed by manual vacuum aspiration (MVA). However, it requires specialized equipment and skill with some risks of complications like cervical trauma, uterine perforation, infections etc. 
Lately, Misoprostol, a prostaglandin E1 analog, is being used which is a safe, effective and acceptable method to achieve uterine evacuation in incomplete abortion due to its uterotonic properties. ${ }^{3-5}$ Misoprostol is cheap and can be used by different routes viz. per oral, sublingual, buccal, vaginal, and rectal. Similarly, different doses and regimens have been tried in different studies. ${ }^{6}$

With the availability of this non-invasive management option, women are more inclined to accept this procedure. Furthermore, it doesn't require the surgical skills required to perform MVA. This study aims to find out about the safety, efficacy, and acceptability of misoprostol in comparison to MVA for the treatment of incomplete abortion.

\section{MATERIALS AND METHODS}

This was a prospective comparative interventional study, conducted at Paropakar Maternity and Women's Hospital, from October 2011 to March 2012. The study was conducted after approval from the hospital ethical committee. All patients fulfilling inclusion criteria were explained about the study, nature of the drug, it's side effects, possible limitations, and complications. The patients were included in the study after written consent was obtained. All women with clinical or ultrasound diagnosis incomplete abortion with less than 13 weeks of gestation according to the last menstrual period were included in the study. Patients with a uterine scar, septic/induced abortion, excessive bleeding, hemodynamically unstable, hemoglobin $<8$ gm $\%$, patient with active liver injury, lung and heart disease and patient known to allergy to E1 prostaglandin were excluded from the study. All the patients were divided into two groups: Group 1 included all odd numbers of cases under study group to whom Misoprostol $600 \mathrm{mcg}$ was given orally. Group 2 included all even the number of cases under study group to whom MVA was done as standard treatment.

Women allocated to Group 1 were given Misoprostol $600 \mathrm{mcg}$ orally. Women allocated to Group 2 were transferred to MVA room where trained staff did MVA. All women were given prophylactic antibiotics and Ibuprofen was prescribed for pain management if required. Both groups were observed for 4-6 hours and then discharged (except in case of continued and heavy per vaginal bleeding). They were also instructed to call the researcher if vaginal bleeding exceeded two soaked sanitary napkins in one hour for two consecutive hours. All women were asked to follow up after 7 days of treatment and each women's abortion status were assessed via clinical examination, including an interview and bimanual examination. Women with a substantial retained product of conception in the uterus on study day 7 were given the option of waiting an additional week for the uterus to evacuate on its own. Those unwilling to wait underwent MVA. If bleeding persisted after 2 weeks after examination pelvic ultrasound was performed and MVA was done in case of presence of the retained product of conception.

During follow up the success of the procedure, the amount of blood loss, side effects of drugs, satisfaction, acceptability were enquired. Success was defined as complete uterine evacuation without the need for MVA in the medical management group and without the need for repeat vacuum aspiration in the surgical management group. Pain level was measured using a visual analog scale in which circles ranging in size from small (no pain) to large (intense pain ) were used. The intraoperative blood loss was measured as the volume of the uterine aspirate after sieving away the POC in the MVA group. The amount of blood loss in the Misoprostol group was estimated on the basis of the number of pads soaked assuming that one sanitary pad soaked $50 \mathrm{ml}$ blood. Bleeding during the period from the initial period up to follow up visit was noted as an adverse effect and was categorized as heavy bleeding ( $>$ menses, normal bleeding (= menses), light bleeding ( $<$ menses). To assess woman's satisfaction and acceptability, each participant was asked to mention the best and worst feature of her treatment and to indicate whether she would select the treatment again and recommend it to friends or not.

Statistical data analysis was done using SPSS (statistical package for social sciences). Statistical tests carried out for testing the significance were the Chi-square test and Student t-test. Values of $\mathrm{P}<0.05$ were taken to indicate significance.

\section{RESULTS}

Among 1014 Gynecological admissions during the study period, 180 cases were of incomplete abortion. Out of them, 60 cases of incomplete abortion were enrolled in this study. 30 women were randomized into the Misoprostol group and 30 women were randomized into the MVA group. On most background characteristics the two groups didn't differ. (Table 1) Most of the patients were between $15-34$ year age group. Most of the patients had more than 1 parity $(n=45 ; 75.0 \%)$.

Table 1: Distribution of patient according to age, parity, and period of gestation $(n=60)$

\begin{tabular}{llll}
\hline Variables & \multicolumn{1}{c}{$\begin{array}{c}\text { Group 1 } \\
\mathbf{n}(\%)\end{array}$} & $\begin{array}{c}\text { Group 2 } \\
\mathbf{n}(\%)\end{array}$ \\
\hline Age group(years) & $15-24$ & $13(43.33)$ & $17(56.66)$ \\
& $25-34$ & $16(53.33)$ & $13(49.33)$ \\
\hline & $35-44$ & $1(3.33)$ & 0 \\
\hline Parity & 0 & $9(30)$ & $16(53.33)$ \\
& $>1$ & $21(70)$ & $14(46.66)$ \\
\hline $\begin{array}{l}\text { Period of gestation } \\
\text { (POG) }\end{array}$ & $6-8$ weeks & $2(6.66)$ & $4(13.33)$ \\
& $8-10$ weeks & $10(33.33)$ & $8(26.66)$ \\
& $10-12$ weeks & $18(60)$ & $18(60)$ \\
\hline
\end{tabular}

The success rate in the two groups was very high (misoprostol-93.33\%; MVA- 100\%) and not statistically significant $(\mathrm{p}>0.05)$. Two patients $(6.66 \%)$ in Group 1 had confirmed incomplete evacuation of the uterus by clinical examination on follow up and were subjected to MVA.

At follow up women in the misoprostol group experienced a significantly higher rate of adverse effects than MVA group (Table 2). Diarrhoea, vomiting and fever were some of the more common incidences among the group 1 patient. In group 2, there were significantly low adverse effects. The common complaints were high pain score $(n=24 ; 80 \%)$ followed by headache $(n=7$; $23.3 \%$ ). 
Table 2: Side effects complained by the study population

\begin{tabular}{|llll}
\hline Type of side effects & $\begin{array}{c}\text { Group } \\
\text { n (\%) }\end{array}$ & $\begin{array}{l}\text { Group 2 } \\
\text { n (\%) }\end{array}$ & p-value \\
\hline Fever & $6(20)$ & 0 & $<0.05$ \\
\hline Chill & $4(13.33)$ & 0 & \\
\hline Cramp & $9(30)$ & $13(43.33)$ & \\
\hline Diarrhea & $14(46.66)$ & 0 & $<0.001$ \\
\hline Vomiting & $8(26.66)$ & 0 & $<0.05$ \\
\hline Dizziness & $5(16.66)$ & $3(10)$ & \\
\hline Headache & $5(16.66)$ & $7(23.33)$ & \\
\hline Cervical laceration & 0 & $2(6.66)$ & \\
\hline Heavy bleeding & $4(13.33)$ & 0 & $<0.001$ \\
\hline Pain score $(>4)$ & $3(10)$ & $24(80)$ & $<0.001$ \\
\hline
\end{tabular}

In spite of the adverse effects of both procedures, women of the Misoprostol group were more satisfied than the MVA group (Table 3).

Table 3: Satisfaction of level of the study population

\begin{tabular}{lll}
\hline Satisfaction & Group 1 Number (\%) & Group 2 Number (\%) \\
\hline Satisfied & $22(73.33)$ & $22(77.33)$ \\
\hline Very satisfied & $4(13.33)$ & 0 \\
\hline Unsatisfied & $4(13.33)$ & $8(26.66)$ \\
\hline
\end{tabular}

\section{DISCUSSION}

In the current study, the complete uterine evacuation rate was similar in both groups with a slight higher success rate in the MVA group. A similar finding was reported by Shwekerela et al in a study from Tanzania ${ }^{7}$ and Montesionus et al. ${ }^{8}$ In contrast to this finding, a study by Week's et al in Uganda showed Misoprostol to be more effective than MVA $(96 \%$ vs. $92 \%) .{ }^{9}$ While in other studies by Bano et al and Bique et al the success rate of MVA was $100 \%$ effective while Misoprostol was $92 \%$ and $91 \%$ effective. ${ }^{10,11}$ Similarly, in a study done by Ibiyemi KF et al, the success rate of MVA versus Misoprostol was $99 \%$ and $83 \%$ respectively. ${ }^{12}$ The high success in our study is likely due to limited use of ultrasound and larger duration of follow up 14 days as shown by Tang et al. ${ }^{13}$

Regarding the safety of both treatment modalities, the present study demonstrated that women's in the misoprostol group experienced more side effects than women in the MVA group. In Misoprostol group fever was a common and statistically significant side effect as compared to MVA group. A similar finding was observed by other studies. ${ }^{7,911,14}$ The reason behind it is due to the main action of Misoprostol in central thermoregulatory centre. $^{15}$

\section{REFERENCES}

1. World Health Organization. Unsafe abortion:global and regional estimates of incidence of mortality due to unsafe abortion with a listing of available country data. 6th edition, Geneva: WHO;2011. Crossref

2. Stoval T. Early Pregnancy Loss and Ectopic Pregnancy. In, Lippincott Williams and Wilkins (ed). Berek and Novak's Gynecology, 14th edition. New Delhi, Wolters Kluwer Health (India) Pvt. Ltd, 2007;261p.
Another common side effect was per vaginal bleeding in the Misoprostol group which is similar to a study conducted by Montensionus et $\mathrm{al}^{8}$ where the bleeding was encountered in $22.6 \%$ patients in the misoprostol group in compared to only $6.7 \%$ in MVA group. MVA was identified as more painful than misoprostol $(24 ; 80 \%)$, which is in agreement with a study done by Shwekerela et al. ${ }^{7}$ and Bique et al ${ }^{11}$ but in contrast to Niinimaki et al. ${ }^{16}$

Diarrhea was found significantly high in Misoprostol than MVA group which was a similar finding in a study done by Pang et al. ${ }^{17}$ In contrast, Phuong et al showed a low incidence of diarrhea in a single-dose regimen of misoprostol. ${ }^{18}$ Misoprostol group showed significantly high cases of vomiting than the MVA group, which is similar to a study carried by Tang et al. ${ }^{13}$, In contrast, there was a low incidence of vomiting in a study conducted by Pang et al. ${ }^{17}$ It is hypothesized that the high peak plasma concentration of misoprostol was cause of increased systemic side effects. ${ }^{19}$

In spite of the adverse effects of both procedures, these side effects are transient and tolerable. As in other studies, the current participants include high satisfaction with both the misoprostol and the MVA group. ${ }^{7,8,20}$ This finding was contrary to a study by Shwekerale et al where misoprostol had a significantly higher percentage of participant satisfaction than the MVA group (75\% versus $55 \%)(\mathrm{P}=0.001) .^{7}$ A comparatively high percentage of participants from both groups, in this study, expressed a desire to recommend their treatment method, which is in line with the findings of Dao et al. ${ }^{19}$ In contrast, Shwekerale et al's study determined that a significantly higher proportion of participant in the Misoprostol group would recommend the treatment to friend than in MVA group ( 95 vs $75 \% ; \mathrm{p}<0.001$ ). ${ }^{7}$ The high satisfaction in both the procedures is due to availability with ease, shorter hospital stay, fewer complications.

In a poor country like ours where surgical evacuation facilities are limited, lack of skilled surgical providers and equipment, the use of $600 \mathrm{mcg}$ Misoprostol orally, by health providers, can be life-saving and help us in reducing maternal mortality. Although Misoprostol is a very effective drug, the health care professional should have thorough knowledge of the dose, side effects, complications and contraindications before prescribing it.

\section{CONCLUSIONS}

The efficacy of oral Misoprostoiis is as effective as MVA in the treatment of first trimester incomplete abortion with comparable success rate. Though Misoprostol had more side effects it's satisfaction and acceptability were comparable with the MVA group.

3. Ancum WM, Van der Veen F. Expectant management of firsttrimester spontaneous abortion. Lancet. 1995;345:1179-80. Crossref

4. Trinder J, Brocklehurst P, Porter R, Read M, Vyas S, Smith L. Management of miscarriage: expectant, medical or surgical? Results of randomized controlled trial, miscarriage treatment(MIST trial). Br J Obstet Gynecol. 2006;332:1235-8. Crossref 
5. Moodliar S, Bagrattee JS, Moodly J. Medical versus surgical evacuation of first trimester spontaneous abortion. Int $\mathrm{J}$ Gynaecol . 2005;353:761-9. Crossref

6. Creinin MD, Harwood B, Guido RS, Fox MC, Zhang J, NICHD Management of Early Pregnancy Failure Trial. Endometrial thickness after misoprostol use for early pregnancy failure. International Journal of Gynecology \& Obstetrics. 2004 Jul;86(1):22-6. Crossref

7. Shwekerela B, Kalumuna R, Kipingili R et al. Misoprostol for treatment of incomplete abortion at the regional hospital level: results from Tanzania. BJOG 2007;114:1363-67. $\underline{\text { Crossref }}$

8. Montesinos R, Durocher J, Leon W et al. Oral Misoprostol for the management of incomplete abortion in Equador. Int $\mathrm{J}$ Gynaecol Obstet. 2011;115(2):135-39. Crossref

9. Weeks A, Alia G, Blum J et al. A Randomized Trial of Misoprostol Compared with Manual Vacuum Aspiration for Incomplete Abortion. ACOG 2005;106:540-7. Crossref

10. Bano K, Talat, Iqbal S. Alternative to Surgical Evacuation of uterus: Misoprostol for Post Abortion Care. Journal of Surgery Pak (Inter) 2009;14(2):53-7.

11. Bique C, Usta M, Debora B, Chong E, Westheimer E, Winikoff B. Comparison of Misoprostol and Manual Vacuum Aspiration for the treatment of incomplete abortion. Int J Gynecol Obstet 2007;98:2226. Crossref

12. Ibiyemi KF, Ijaiya MA, Adesina KT. Randomised Trial of Oral Misoprostol versus Manual Vacuum Aspiration for the Treatment of Incomplete abortion at a Nigerian Tertiary Hospital. SQU Medical Journal 2019;19(2):3. Crossref

13. Tang OS, Gemzell-Danielsson K, Ho PC. Misoprostol: pharmokinetics profiles, effects on uterus and side effect. Int $\mathbf{J}$
Gynecol Obstet 2007;99:160-7. $\underline{\text { Crossref }}$

14. Das CM, Sharma M, Pardeep K, Khurshid F. To Compare the Safety and Efficacy of Manual Vacuum Aspiration with Misoprostol $600 \mathrm{mcg}$ in Incomplete Miscarriage. J Liaquat Uni Health Sci 2014;9(13):3.

15. Elati A, Weeks A. Risk of fever after misoprostol for the prevention of postpartum hemorrhage: A meta-analysis. Obstet Gynecol 2012;120:1140-1148. Crossref

16. Ninimaki M, Jouppila P, Martikainen H, Talvenssari-Mattila A. A randomized study comparing efficacy and patient satisfaction in medical or surgical treatment of Miscarriage. Fertil Steril 2006;86:372-76. $\underline{\text { Crossref }}$

17. Pang MW, Lee TS, Chung TKH. Incomplete miscarriage: a randomized controlled trial comparing oral with vaginal Misoprostol for medical evacuation. Oxford Journals Medicine Hum Reprod 2001;16:2283-87. $\underline{\text { Crossref }}$

18. Phupong V, Taneepaniohskul S, Kriengsinvot R, Sriyirojana N, Blanchard K, Winikoff B. Comparitive study between single-dose $600 \mathrm{mcg}$ and repeated dose of oral misoprostol for treatment of incomplete abortion. Contraception 2004;70(4):307-11. Crossref

19. Zieman M, Fory SK, Benowitz NL, Barskter D, Darney PD. Abortion kinetics of different routes of administration of misoprostol. Hum Reprod 2000;17:33

20. Taylor J, Diop A, Blum J, Dolo O, Winikoff B. Oral Misoprostol as an alternative to surgical management for incomplete abortion in Ghana. Int J Gynecol Obstet 2011:112:40-4. $\underline{\text { Crossref }}$

21. 21. Dao B, Blum J, Thieba B et al. Is Misoprostol a safe, effective and acceptable alternative to MVA for post abortion care? Results from a randomized trial in Burkina Faso, West Africa. BJOG 2007;10:1471- 0528. Crossref 